\title{
Identifying unprovoked thromboembolism patients at low risk for recurrence who can discontinue anticoagulant therapy
}

\author{
Marc A. Rodger MD MSc, Susan R. Kahn MD MSc, Philip S. Wells MD MSc, David A. Anderson MD, \\ Isabelle Chagnon MD, Grégoire Le Gal MD PhD, Susan Solymoss MD, Mark Crowther MD, \\ Arnaud Perrier MD, Richard White MD, Linda Vickars MD, Tim Ramsay PhD MSc, \\ Marisol T. Betancourt MD MSc, Michael J. Kovacs MD
}

$\infty \quad$ See related commentary by Kearon, page 401

\section{ABSTRACT}

Background: Whether to continue oral anticoagulant therapy beyond 6 months after an "unprovoked" venous thromboembolism is controversial. We sought to determine clinical predictors to identify patients who are at low risk of recurrent venous thromboembolism who could safely discontinue oral anticoagulants.

Methods: In a multicentre prospective cohort study, 646 participants with a first, unprovoked major venous thromboembolism were enrolled over a 4-year period. Of these, 600 participants completed a mean 18-month follow-up in September 2006. We collected data for 69 potential predictors of recurrent venous thromboembolism while patients were taking oral anticoagulation therapy (5-7 months after initiation). During follow-up after discontinuing oral anticoagulation therapy, all episodes of suspected recurrent venous thromboembolism were independently adjudicated. We performed a multivariable analysis of predictor variables $(p<0.10)$ with high interobserver reliability to derive a clinical decision rule.

Results: We identified 91 confirmed episodes of recurrent venous thromboembolism during follow-up after discontinuing oral anticoagulation therapy (annual risk 9.3\%, $95 \% \mathrm{Cl} 7.7 \%-11.3 \%)$. Men had a $13.7 \%$ (95\% Cl $10.8 \%-$ $17.0 \%)$ annual risk. There was no combination of clinical predictors that satisfied our criteria for identifying a lowrisk subgroup of men. Fifty-two percent of women had 0 or 1 of the following characteristics: hyperpigmentation, edema or redness of either leg; D-dimer $\geq 250 \mu \mathrm{g} / \mathrm{L}$ while taking warfarin; body mass index $\geq 30 \mathrm{~kg} / \mathrm{m}^{2}$; or age $\geq 65$ years. These women had an annual risk of $1.6 \%(95 \% \mathrm{Cl}$ $0.3 \%-4.6 \%)$. Women who had 2 or more of these findings had an annual risk of $14.1 \%$ (95\% Cl 10.9\%-17.3\%).

Interpretation: Women with 0 or 1 risk factor may safely discontinue oral anticoagulant therapy after 6 months of therapy following a first unprovoked venous thromboembolism. This criterion does not apply to men. (http://Clinicaltrials.gov trial register number NCT00261014)

Une version française de ce résumé est disponible à l'adresse www.cmaj.ca/cgi/content/full/179/5/417/DC1

CMAJ 2008;179(5):417-26
$\mathrm{V}$ enous thromboembolism is a common, potentially fatal, yet treatable, condition. The risk of a recurrent venous thromboembolic event after 3-6 months of oral anticoagulant therapy varies. Some groups of patients (e.g., those who had a venous thromboembolism after surgery) have a very low annual risk of recurrence $(<1 \%),{ }^{1}$ and they can safely discontinue anticoagulant therapy. ${ }^{2}$ However, among patients with an unprovoked thromboembolism who discontine anticoagulation therapy after 3-6 months, the risk of a recurrence in the first year is $5 \%-27 \% .^{3-6}$ In the second year, the risk is estimated to be $5 \%,{ }^{3}$ and it is estimated to be $2 \%-3.8 \%$ for each subsequent year. ${ }^{5.7}$ The casefatality rate for recurrent venous thromboembolism is between $5 \%$ and $13 \% .^{8.9}$ Oral anticoagulation therapy is very effective for reducing the risk of recurrence during therapy (>90\% relative risk [RR] reduction), ${ }^{3,4,10,11}$ however, this benefit is lost after therapy is discontinued. ${ }^{3,10,11}$ The risk of major bleeding with ongoing oral anticoagulation therapy among venous thromboembolism patients is $0.9-3.0 \%$ per year, ${ }^{3,4,6,12}$ with an estimated case-fatality rate of $13 \% .^{13}$

Given that the long-term risk of fatal hemorrhage appears to balance the risk of fatal recurrent pulmonary embolism among patients with an unprovoked venous thromboembolism, clinicians are unsure if continuing oral anticoagulation therapy beyond 6 months is necessary. ${ }^{2,14}$ Identifying subgroups of patients with an annual risk of less than 3\% will help clinicians decide which patients can safely discontinue anticoagulant therapy.

From the Thrombosis Program, Division of Hematology, Department of Medicine (Rodger, Wells, Ramsay, Betancourt), University of Ottawa; Clinical Epidemiology Unit, Ottawa Health Research Institute (Rodger, Wells, Ramsay, Betancourt), The Ottawa Hospital, Ottawa, Ont.; Department of Medicine (Kahn, Solymoss), McGill University, Montréal, Que.; Centre for Clinical Epidemiology and Community Studies (Kahn), Jewish General Hospital, Montréal, Que.; Department of Medicine (Anderson), Dalhousie University, Halifax, NS; Department of Medicine, Hôpital du Sacré-Coeur de Montréal (Chagnon), University of Montreal, Montréal, Que.; University Hospital and the Department of Internal Medicine and Chest Diseases (Le Gal), Brest, France; Department of Medicine, Michael G. DeGroote School of Medicine (Crowther), McMaster University, Hamilton, Ont.; Department of Internal Medicine, Geneva University Hospital, and the Faculty of Medicine (Perrier), Geneva, Switzerland; Department of Medicine, UC Davis School of Medicine (White), Sacramento, Calif.; Department of Medicine, St. Paul's Hospital (Vickars), University of British Columbia, Vancouver, BC; Division of Hematology, Department of Medicine (Kovacs), University of Western Ontario, London, Ont. 
We sought to determine the clinical predictors or combinations of predictors that identify patients with an annual risk of venous thromboembolism of less than 3\% after taking an oral anticoagulant for 5-7 months after a first unprovoked event.

\section{Materials and methods}

\section{Study design and selection of participants}

We performed a prospective clinical decision-rule derivation cohort study and a split-sample validation study that included consecutive unselected patients from 12 tertiary care centres in 4 countries. We included patients whose first, objectively proven unprovoked thromboembolism (proximal deep vein thrombosis, or segmental or greater pulmonary embolism) occurred 5-7 months before enrollment. We included patients who received heparin or low-molecular-weight heparin for 5 or more days and who received oral anticoagulation therapy for 5-7 months after the event (target international normalized ratio 2-3). We also included patients if they had not had a recurrent venous thromboembolism during the treatment period. Objective documentation of deep vein thrombosis required the presence of a noncompressible segment on a compression ultrasound of the popliteal vein or a more proximal leg vein. Objective documentation of a pulmonary embolism required a high-probability ventilation-perfusion scan or a segmental or larger artery filling defect on a spiral computed tomography (CT) scan. We defined an unprovoked index venous thromboembolism as one that occurred in the absence of a leg fracture or lower-extremity plaster cast, immobilization for greater than 3 days or surgery using a general anesthetic in the 3 months before the index event, and without the diagnosis of a malignant disease in the past 5 years.

We excluded patients who were unable or unwilling to provide written informed consent, were aged 17 years or younger, had already discontinued oral anticoagulants, required ongoing anticoagulation for reasons other than venous thromboembolism, were geographically inaccessible for follow-up, were being treated for a recurrent unprovoked venous thromboembolism or "known" high-risk thrombophilia (defined as known deficiency of protein $\mathrm{S}$, protein $\mathrm{C}$ or antithrombin, known persistently positive anticardiolipin antibodies [ $>30 \mathrm{U} / \mathrm{mL}$ ], a known persistently positive lupus anticoagulant, or who had 2 or more known thrombophilic defects [e.g., homozygous for factor V Leiden or prothrombin gene mutation, or compound heterozygous for factor V Leiden and prothrombin gene mutation]). We did not perform thrombophilia testing before enrollment; however, we excluded patients with high-risk thrombophilia if it had been independently identified before enrollment.

We obtained approval from the institutional research ethics board at all participating centres (Ottawa Hospital Research Ethics Board for the lead institution).

\section{Baseline patient assessment}

We performed an assessment 5-7 months after the index venous thromboembolism event while patients were receiving oral anticoagulant therapy. We collected data for 69 independent variables identified in a systematic review conducted a priori and periodically updated throughout the study (Appendix 1, available online at www.cmaj.ca/cgi/content/full/179/5/417/DC2).
We collected data about demographic characteristics, risk factors for venous thromboembolism at the time of index event, patient-reported post-thrombotic symptoms, concomitant medications, results of thrombophilia testing, and imaging reports confirming the index venous thromboembolism event. In addition, study nurses performed a physical examination of each patient, recording height and weight. Nurses also performed a standardized evaluation of post-thrombotic signs for both legs.

We obtained samples for laboratory analysis while patients were taking oral anticoagulants. A complete blood count was performed and homocysteine levels were analyzed at local clinical laboratories. Standard protocols were used to extract DNA from peripheral blood leukocytes, and an ABI PRISM 3100 genetic analyzer (Applied Biosystems) was used to test for factor V Leiden and to perform prothrombin gene variant genotyping by use of established methods..$^{15} \mathrm{We}$ also obtained samples to test for the levels of factor VIII, D-dimer, lupus anticoagulant and anticardiolipin IgG and IgM. These samples were processed and stored locally, but they were shipped on dry ice and analyzed centrally at the London Health Sciences Centre. Within 1 hour of collection, plasma samples were double centrifuged at $2500 \mathrm{~g}$ for 20 minutes and frozen immediately at $-70^{\circ} \mathrm{C}$. D-Dimer testing was performed using the Vidas D-dimer reagent on the Vidas Instrument (bioMérieux). Coagulation assays were performed on an ACL 9000 instrument (Instrumentation Laboratory). We used the HemosIL APTT-SP reagent to test for factor VIII, and we tested for lupus anticoagulant using dilute Russel viper venom time (HemosIL LAC screen) with LAC Confirm reagents (Instrumentation Laboratory). Anticardiolipin antibodies (IgG and $\operatorname{IgM}$ ) were tested for using commercially available enzyme-linked immunosorbent assay kits (Louisville APL Diagnostics).

We performed baseline imaging using compression ultrasonography of the leg that was symptomatic at the time of the index event. If the patient had signs or symptoms of a pulmonary embolism at the time of index event, a ventilationperfusion scan was also performed.

\section{Follow-up and outcome assessment}

Patients were instructed to contact study personnel if they developed symptoms of recurrent venous thromboembolism. Patients were seen in clinic every 6 months and were asked about whether they had any symptoms of venous thromboembolism. Participants were withdrawn and their data censored if they withdrew consent or started anticoagulant therapy (reasons for starting anticoagulants were documented).

All suspected venous thromboembolism events and deaths were independently adjudicated by physicians (M.R., S.K., P.W., D.A., M.K., G.L.) who were blinded to the predictor data. All patients with a suspected recurrent venous thromboembolism who presented with leg symptoms underwent compression leg vein ultrasonography or venography. The criteria for diagnosis of recurrent deep vein thrombosis have been previously described.$^{16}$ All patients with a suspected pulmonary embolism had a ventilation-perfusion scan. If results of the scan were normal, unchanged or better than those from the baseline exam, we excluded the diagnosis of pulmonary 
embolism. If the ventilation-perfusion scan showed a new mismatched segmental defect or a greater perfusion defect compared with baseline, a pulmonary embolism was diagnosed. If a new matched or subsegmental perfusion defect was found, we performed a spiral CT scan. If this scan showed an intraluminal filling defect in a segmental or larger artery in an area that had normal perfusion in the baseline ventilation-perfusion scan, a pulmonary embolism was diagnosed. All other patients were required to undergo pulmonary angiography to diagnose or exclude suspected recurrent pulmonary embolism. We also considered pulmonary embolism found at autopsy to be diagnostic of recurrent venous thromboembolism.

\section{Data analysis}

We first performed univariable analyses to determine the strength of association between each potential predictor variable and recurrence of venous thromboembolism. All potentially significant $(p<0.20)$ continuous variables were dichotomized at varying cut-off points, and the optimal cut-off points were identified (i.e., the cut-off points with the highest $\chi^{2}$ value). We used dichotomous variables to make the final clinical decision rule easier to remember and apply. We then assessed the dichotomized variables with $p<0.10$ for interobserver reliability. Variables with previously published high reproducibility were retained. For those without published evidence of reproducibility, we conducted interobserver reliability studies. We retained variables with a kappa score greater than 0.6 . This process aided in the selection of the best variables for the multivariable analysis.

Using conditional logistic regression with forward variable selection, we conducted multivariable analysis with recurrent venous thromboembolism as the dependent variable. The study steering committee (M.R., M.K., P.W., G.L., A.P., R.W., S.K., D.A.) derived and reviewed 5 candidate clinical decision rules for women and 2 for men. These rules were selected based on classification performance (annual risk of recurrence in the low-risk group, defined a priori as a target of $<3 \%$ ), proportion of patients identified as low risk, face validity, ease of use and fewest predictor variables. We performed split-sample cross-validation by determining the classification performance of a short list of candidate clinical decision rules for 500 subsamples. Each subsample consisted of randomly chosen patients from the study population. The size of each subsample was $50 \%$ of the study population. We rejected any decision rule for which any of the 500 samples had a greater than $3 \%$ annual risk of recurrence. We further internally assessed the performance of the final clinical decision rules using the subset of patients whose data could not be included in the derivation of the rule because of missing data.

\section{Funding and commercial interests}

This study was funded by the Canadian Institutes of Health Research (grant no. MOP 64319) and bioMérieux. bioMérieux provided funding via an unrestricted research grant. The company did not influence the design, conduct or reporting of the trial.

\section{Results}

Between October 2001 and March 2006, we enrolled 665 participants. Of these, 600 patients completed follow-up in September 2006 (Figure 1). The mean age of participants was

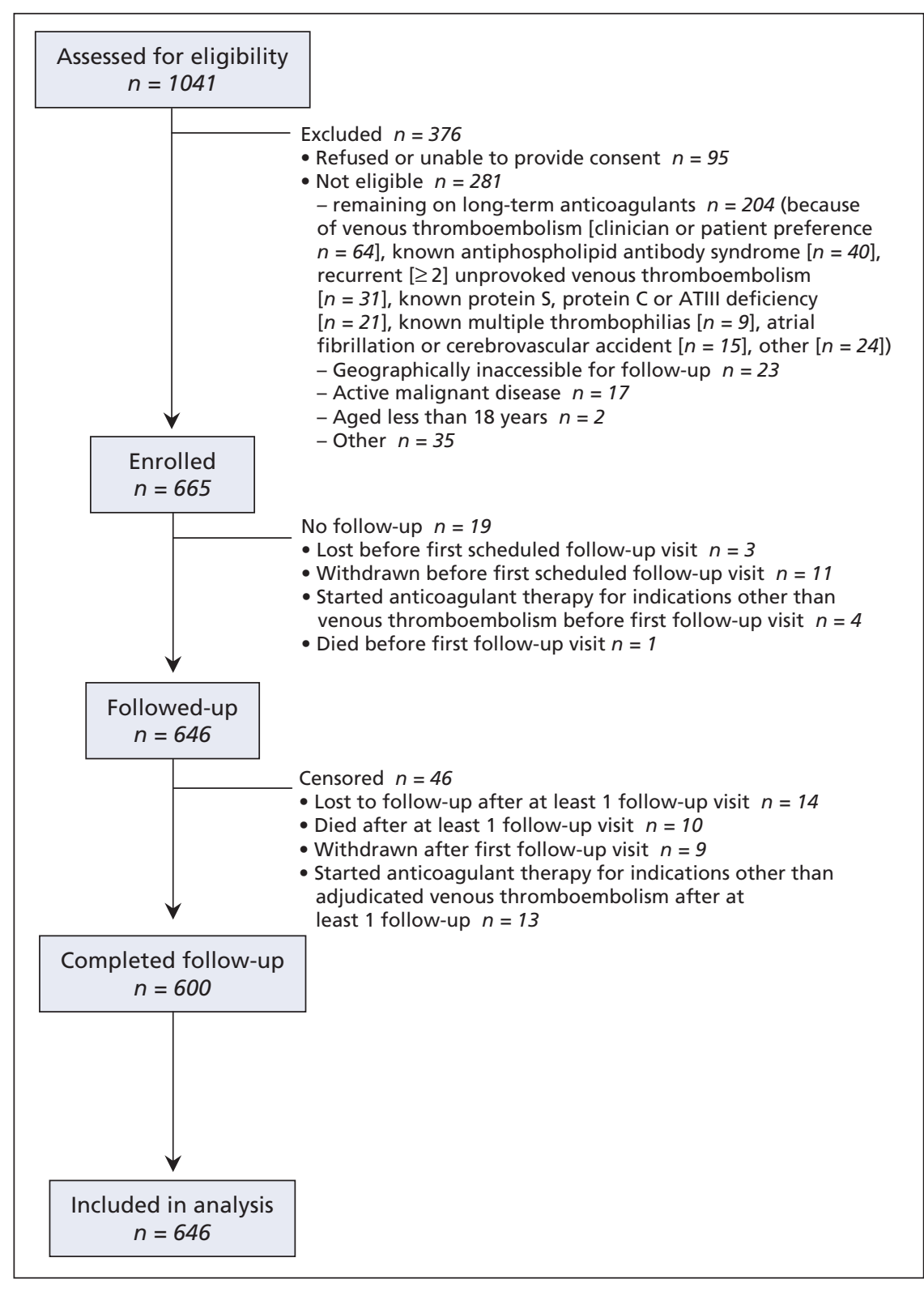

Figure 1: Flow of participants through the study. 


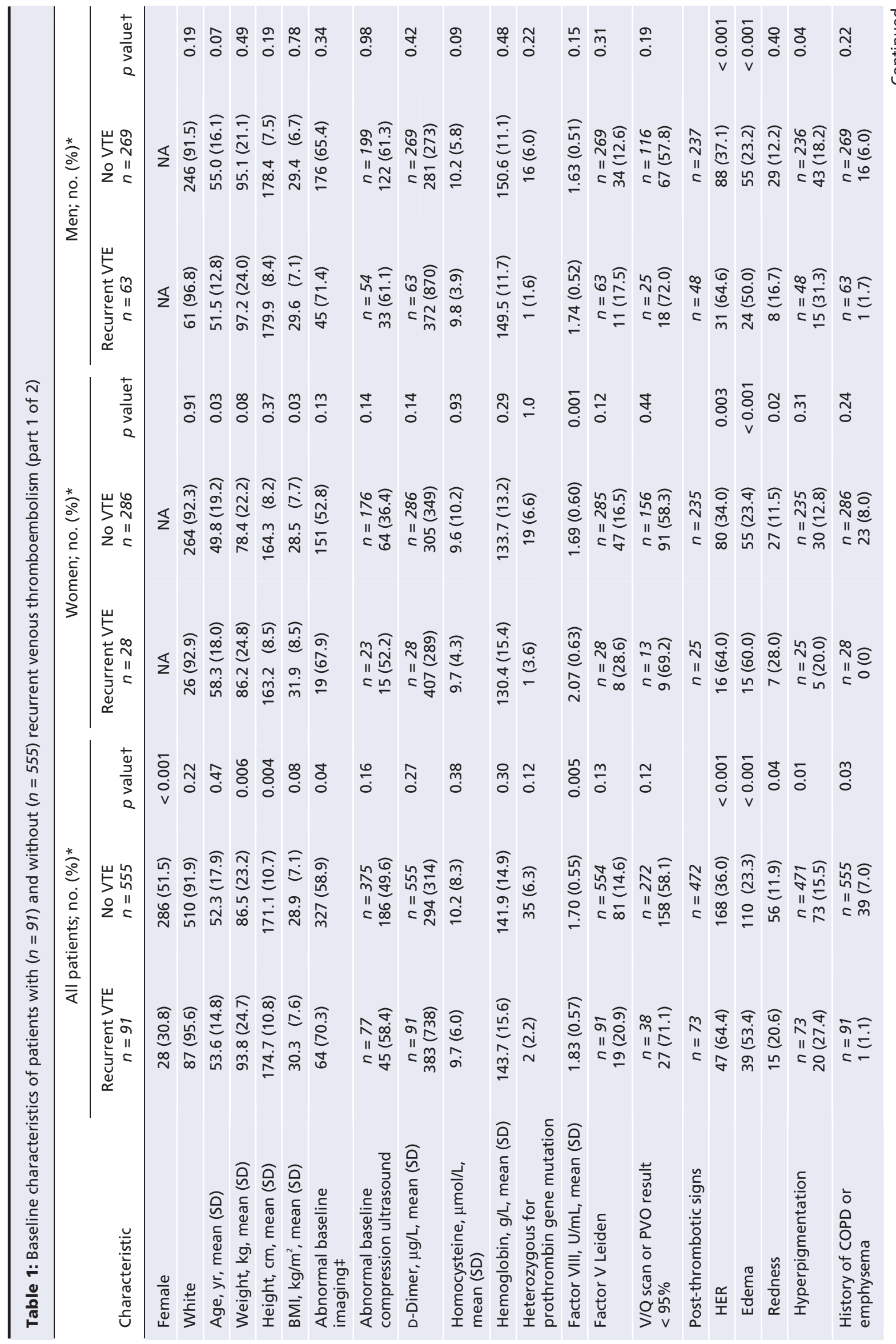




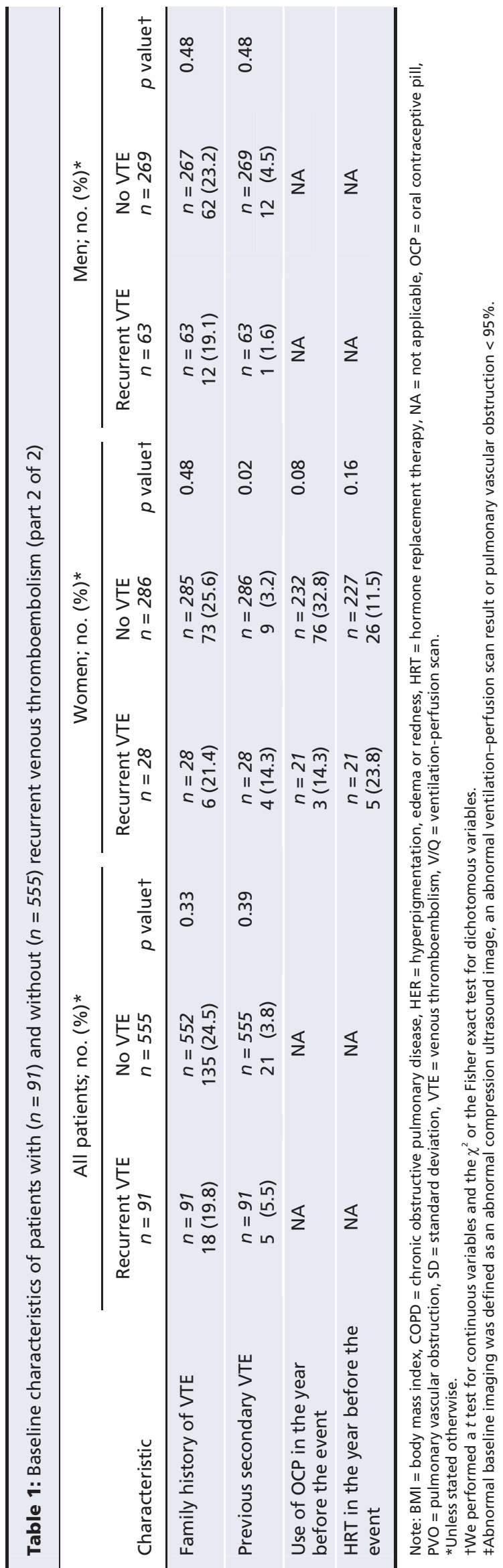

53 (min-max 18-95) years, and 49\% were female (Table 1). Index events included 194 (30\%) isolated pulmonary embolisms, $339(52.5 \%)$ isolated deep vein thrombosis events and $113(17.5 \%)$ events of both deep vein thrombosis and pulmonary embolism. During a mean follow-up interval of 18 (min-max 1-47) months, 91 of 306 suspected recurrent venous thromboembolism were objectively documented, which is equal to a $9.3 \%$ annual risk of recurrent venous thromboembolism (95\% CI 7.7\%-11.3\%). None of the deaths during follow-up were caused by recurrent venous thromboembolism (case-fatality rate 0\%, 95\% CI 0\%-3.2\%).

Table 1 lists potential predictor variables for the study population. Of men, 19\% developed recurrent venous thromboembolism over a mean follow-up of 72 weeks (annual risk 13.7\%, 95\% CI 10.8\%-17.0\%) compared with $8.9 \%$ of women during a mean follow-up of 84 weeks $(5.5 \%$ annual risk, $95 \% \mathrm{CI}$ $3.7 \%-7.8 \%)(p<0.001)$. Men with post-thrombotic symptoms of leg hyperpigmentation, edema or redness had very high risk of recurrence (24.0\% annual risk) (Figure 2).

Initial multivariable modelling failed to identify a clinical decision rule that satisfied our criterion ( $<3 \%$ annual risk) for identifying a low-risk subgroup of men. Thus, we performed a post-hoc stratification of participants by sex, and we repeated the univariable analyses, including identifying optimal cut-off points for each sex strata (Figure 2 and Figure 3). The use of multivariable modelling with sex-specific subgroups led to 5 candidate decision rules for women (Table 2) and 2 for men (Table 3). We performed split sample crossvalidation with the candidate clinical decision rules that had good classification performance, face validity and ease of use. Neither of the candidate clinical decision rules for men had face validity, nor were they statistically validated in the 500 subsample analysis (mean risk $>3 \%$ ).

In total, $52 \%$ of women had 0 or 1 risk factors for recurrent venous thromboembolism (hyperpigmentation, edema or redness of either leg; D-dimer $\geq 250 \mu \mathrm{g} / \mathrm{L}$ while on warfarin; BMI $\geq 30 \mathrm{~kg} / \mathrm{m}^{2}$; age $\geq 65$ years). Among these women, the annual risk of venous thromboembolism was $1.6 \%$ (95\% CI $0.3 \%-$ $4.6 \%)$. Women with 2 or more risk factors had an annual risk of $14.1 \%$ (95\% CI 10.9\%-17.3\%). Of low-risk patients, the annual risk was $1.2 \%$ in the subgroup with index deep vein thrombosis alone, $0 \%$ in the group with index pulmonary embolism alone, $2.1 \%$ in the group with index pulmonary embolism with or without deep vein thrombosis, and $2.5 \%$ in the group with index deep vein thrombosis with or without pulmonary embolism. The survival curve for women at low risk and for those at high risk (men, and women with $\geq 2$ risk factors) are shown in Figure 4. For the 500 subsamples from the derivation set, the mean annual risk of recurrent venous thromboembolism in women at low risk of recurrence was between $0 \%$ and $3.0 \%$.

In total, 124 participants in the derivation set were missing predictor data. Of these, 101 were classifiable as low or high risk of recurrence and were included in the internal validation. In this cohort, women in the low-risk group $(\leq 1$ risk factor) had an annual risk of recurrent venous thromboembolism less than $3 \%$ (annual risk $2.7 \%, 95 \%$ CI $0.3 \%-8.9 \%$ ). Women with 2 or more risk factors had an annual risk of recurrence of $10.2 \%$ (95\% CI 6.2\%-15.1\%). 


\section{Interpretation}

We developed and internally validated a clinical decision rule that may ultimately provide clinicians with guidance as to whether oral anticoagulation therapy can be discontinued after 5-7 months of treatment for an "unprovoked" venous thromboembolism. This clinical decision rule identifies women with an annual risk of venous thromboembolism less

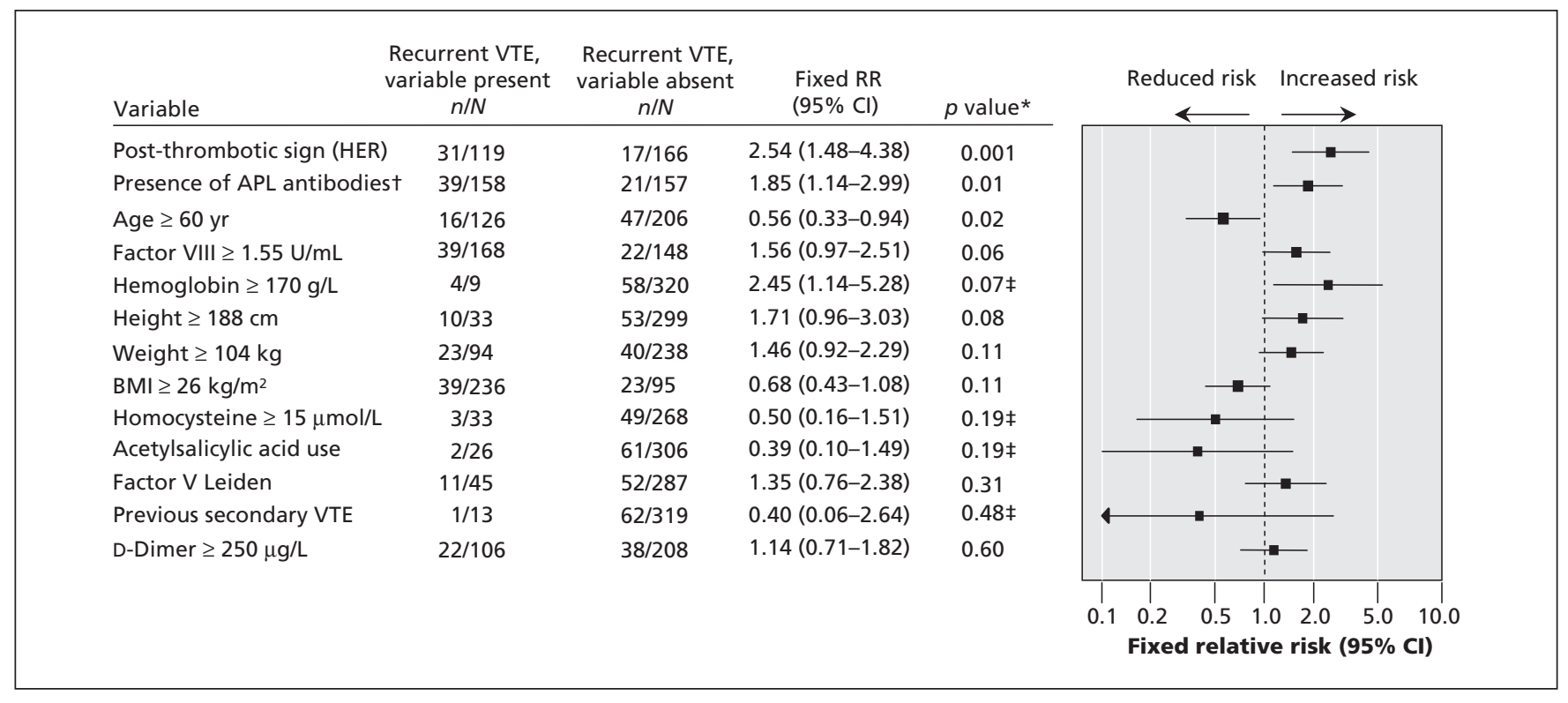

Figure 2: Potential predictor variables for men at optimal cutoff points, by strength of association. *Determined by $\chi^{2}$ testing, unless stated otherwise. +Presence of antiphospholipid (APL) antibodies was determined by anticardiolipin antibody (IgG or $\mathrm{lgM}) \geq 6 \mathrm{U} / \mathrm{mL}$ or by a positive result for lupus anticoagulant. $\neq$ Determined by the Fisher exact test. Note: $\mathrm{BMI}=$ body mass index, $\mathrm{Cl}=\mathrm{confidence}$ interval, $\mathrm{HER}=$ hyperpigmentation, edema or redness, $\mathrm{RR}=$ relative risk, VTE = venous thromboembolism.

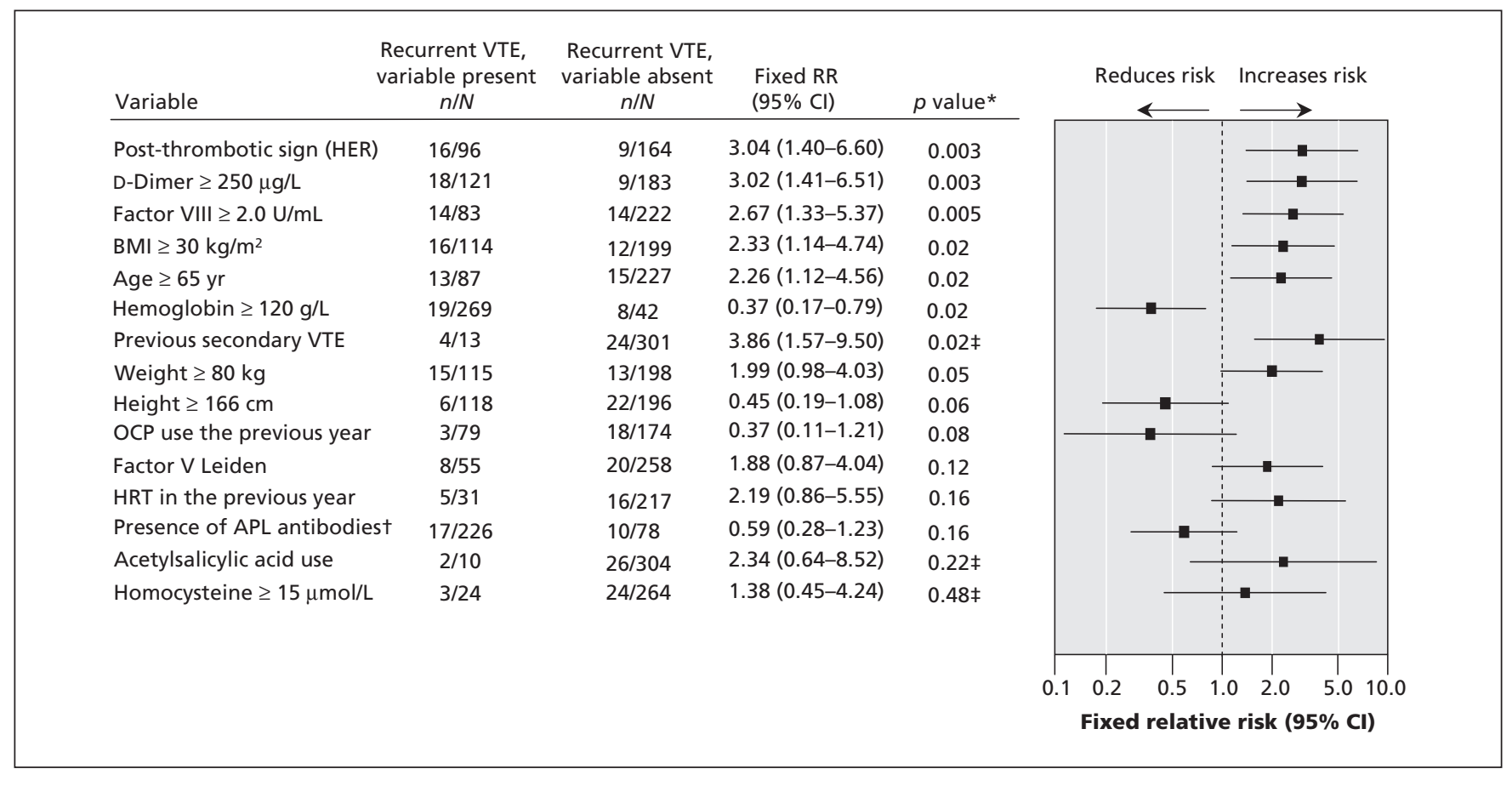

Figure 3: Potential predictor variables for women at optimal cut-off points, by strength of association. *Determined by $\chi^{2}$ testing, unless stated otherwise. †Presence of antiphospholipid (APL) antibodies was determined by anticardiolipin antibody (IgG or IgM) $\geq 4$ $\mathrm{U} / \mathrm{mL}$ or by a positive result for lupus anticoagulant. $\neq$ Determined by the Fisher exact test. Note: $\mathrm{BMI}=$ body mass index, $\mathrm{Cl}=$ confidence interval, HER = hyperpigmentation, edema or redness, HRT = hormone replacement therapy, $\mathrm{OCP}=$ oral contraceptive pills, $\mathrm{RR}=$ relative risk, VTE = venous thromboembolism. 
than $3 \%$ who can likely safely discontinue anticoagulant therapy (Box 1).

Despite research about the duration of anticoagulant treatment for unprovoked venous thromboembolism ${ }^{3,4,11,17,18}$ and the identification of risk factors for its recurrence, ${ }^{19-26}$ clinicians remain vexed as to who should continue taking anticoagulants after an initial 3-6 months of therapy. In fact, practice guidelines have remained unchanged despite a decade of research. ${ }^{2}$ This failure to change practice is likely because a therapy has not been identified that reduces the risk of bleeding below the level of risk of recurrent venous thromboembolism after 3-6 months of anticoagulant therapy (e.g., lower intensity international normalized ratio, new anticoagulants). This failure is also likely because of a failure to identify high-risk groups in which the benefits of standard therapies clearly outweighed the risks and to identify low-risk groups for whom no further therapy is necessary.

A number of variables to stratify risk of recurrent venous thromboembolism in patients with an unprovoked index event have been investigated, including sex, ${ }^{22}$ plasma D-dimer levels

Table 2: Classification performance of the candidate clinical predictor rules for women

\begin{tabular}{|c|c|c|c|c|c|c|c|}
\hline \multirow[b]{2}{*}{ Model } & \multirow[b]{2}{*}{ Variable } & \multirow[b]{2}{*}{ Sensitivity } & \multirow[b]{2}{*}{ Specificity } & \multirow[b]{2}{*}{ NPV } & \multicolumn{2}{|c|}{$\begin{array}{c}\text { Annual risk of recurrent } \\
\text { venous thromboembolism }\end{array}$} & \multirow{2}{*}{$\begin{array}{l}\% \text { of patients } \\
\text { identified by } \\
\text { model as being } \\
\text { at low risk }\end{array}$} \\
\hline & & & & & $\begin{array}{l}\text { Low-risk } \\
\text { group }\end{array}$ & $\begin{array}{l}\text { High-risk } \\
\text { group }\end{array}$ & \\
\hline 1 & $\begin{array}{l}\text { - Hyperpigmentation, edema and redness } \\
\text { - Body mass index } \geq 30 \mathrm{~kg} / \mathrm{m}^{2} \\
\text { - Age } \geq 65 \mathrm{yr}\end{array}$ & 0.89 & 0.37 & 0.97 & $1.6 \%$ & $7.9 \%$ & $34.7 \%$ \\
\hline 2 & $\begin{array}{l}\text { - Hyperpigmentation, edema and redness } \\
\text { - D-Dimer } \geq 250 \mu \mathrm{g} / \mathrm{L} \\
\text { - Body mass index } \geq 30 \mathrm{~kg} / \mathrm{m}^{2}\end{array}$ & 0.88 & 0.38 & 0.97 & $2.3 \%$ & $10.4 \%$ & $35.5 \%$ \\
\hline 3 & $\begin{array}{l}\text { - Hyperpigmentation, edema and redness } \\
\text { - D-Dimer } \geq 250 \mu \mathrm{g} / \mathrm{L} \\
\text { - Body mass index } \geq 30 \mathrm{~kg} / \mathrm{m}^{2} \\
\text { - Age } \geq 65 \mathrm{yr}\end{array}$ & 0.88 & 0.57 & 0.98 & $1.6 \%$ & $14.1 \%$ & $52.2 \%$ \\
\hline 4 & $\begin{array}{l}\text { - Hyperpigmentation, edema and redness } \\
\text { - D-Dimer } \geq 250 \mu \mathrm{g} / \mathrm{L} \\
\text { - Body mass index } \geq 30 \mathrm{~kg} / \mathrm{m}^{2} \\
\text { - Previous secondary VTE }\end{array}$ & 0.76 & 0.65 & 0.96 & $2.9 \%$ & $14.8 \%$ & $38.7 \%$ \\
\hline 5 & $\begin{array}{l}\text { - Hyperpigmentation, edema and redness } \\
\text { - D-Dimer } \geq 250 \mu \mathrm{g} / \mathrm{L} \\
\text { - Body mass index } \geq 30 \mathrm{~kg} / \mathrm{m}^{2} \\
\text { - Previous secondary VTE } \\
\text { - Age } \geq 65 \mathrm{yr}\end{array}$ & 0.88 & 0.56 & 0.98 & $1.7 \%$ & $13.8 \%$ & $51.4 \%$ \\
\hline
\end{tabular}

Note: NPV = negative predictive value, VTE $=$ venous thromboembolism

* Model 3 was selected as the final model for women because it had the smallest annual risk of recurrent venous thromboembolism in the low-risk group, the highest NPV, $>10 \%$ risk of recurrence in the high-risk group, and the highest low-risk excluded proportion. This model was also considered the most parsimonious and easy to remember and apply in the clinical setting.

Table 3: Classification performance of the candidate clinical predictor rules for men

\begin{tabular}{|c|c|c|c|c|c|c|c|}
\hline \multirow[b]{2}{*}{ Model } & \multirow[b]{2}{*}{ Variables } & \multirow[b]{2}{*}{ Sensitivity } & \multirow[b]{2}{*}{ Specificity } & \multirow[b]{2}{*}{ NPV } & \multicolumn{2}{|c|}{$\begin{array}{c}\text { Annual risk of recurrent } \\
\text { venous thromboembolism }\end{array}$} & \multirow{2}{*}{$\begin{array}{l}\% \text { of patients } \\
\text { identified by } \\
\text { model as being } \\
\text { at low risk }\end{array}$} \\
\hline & & & & & $\begin{array}{l}\text { Low-risk } \\
\text { group }\end{array}$ & $\begin{array}{l}\text { High-risk } \\
\text { group }\end{array}$ & \\
\hline 1 & $\begin{array}{l}\text { - Hyperpigmentation, edema and redness } \\
\text { - Positive for antiphospholipid antibodies* } \\
\text { - Hemoglobin } \geq 170 \mathrm{~g} / \mathrm{L}\end{array}$ & 0.65 & 0.63 & 0.98 & $3.7 \%$ & $18.8 \%$ & $29.0 \%$ \\
\hline 2 & $\begin{array}{l}\text { - Hyperpigmentation, edema and redness } \\
\text { - Positive for antiphospholipid antibodies* } \\
\text { - Age }<60 \mathrm{yr} \\
\text { - Hemoglobin } \geq 170 \mathrm{~g} / \mathrm{L} \\
\text { - Body mass index }<26 \mathrm{~kg} / \mathrm{m}^{2}\end{array}$ & 0.91 & 0.42 & 0.96 & $3.4 \%$ & $19.9 \%$ & $35.0 \%$ \\
\hline
\end{tabular}

Note: NVP = negative predictive value.

*Anticardiolipin $\geq 6 \mathrm{U} / \mathrm{mL}$ or positive for lupus anticoagulant. 
measured 1-2 months after discontinuation of oral anticoagulants, ${ }^{19,20,23,24}$ residual venous obstruction using venous ultrasonography ${ }^{19,25,26}$ and elevated plasma levels of factor VIII. ${ }^{21}$ Studies investigating these variables have all been hampered by the inclusion of patients with heterogeneous risk of recurrence (e.g., a variable duration of oral anticoagulation therapy, ${ }^{19-21,23,24}$ both provoked and unprovoked index events, ${ }^{19,20,23}$ both distal and proximal deep vein thrombosis ${ }^{23}$ ). Only the use of D-dimer levels as a predictor variable has been studied in a prospective management study. ${ }^{24}$ In this study, a normal D-dimer value after stopping oral anticoagulants was not sufficient to identify patients at low risk (i.e., < 3\% annual risk) to be clinically useful. ${ }^{24}$ Furthermore, stopping anticoagulants, testing D-dimer levels 1 month later and restarting anticoagulant therapy if necessary, is impractical for the majority of patients and exposes high-risk patients to a long period without anticoagulants. We did not find that residual venous obstruction (detected by leg vein imaging) was an important predictor of recurrent venous thromboembolism. We found that ele-

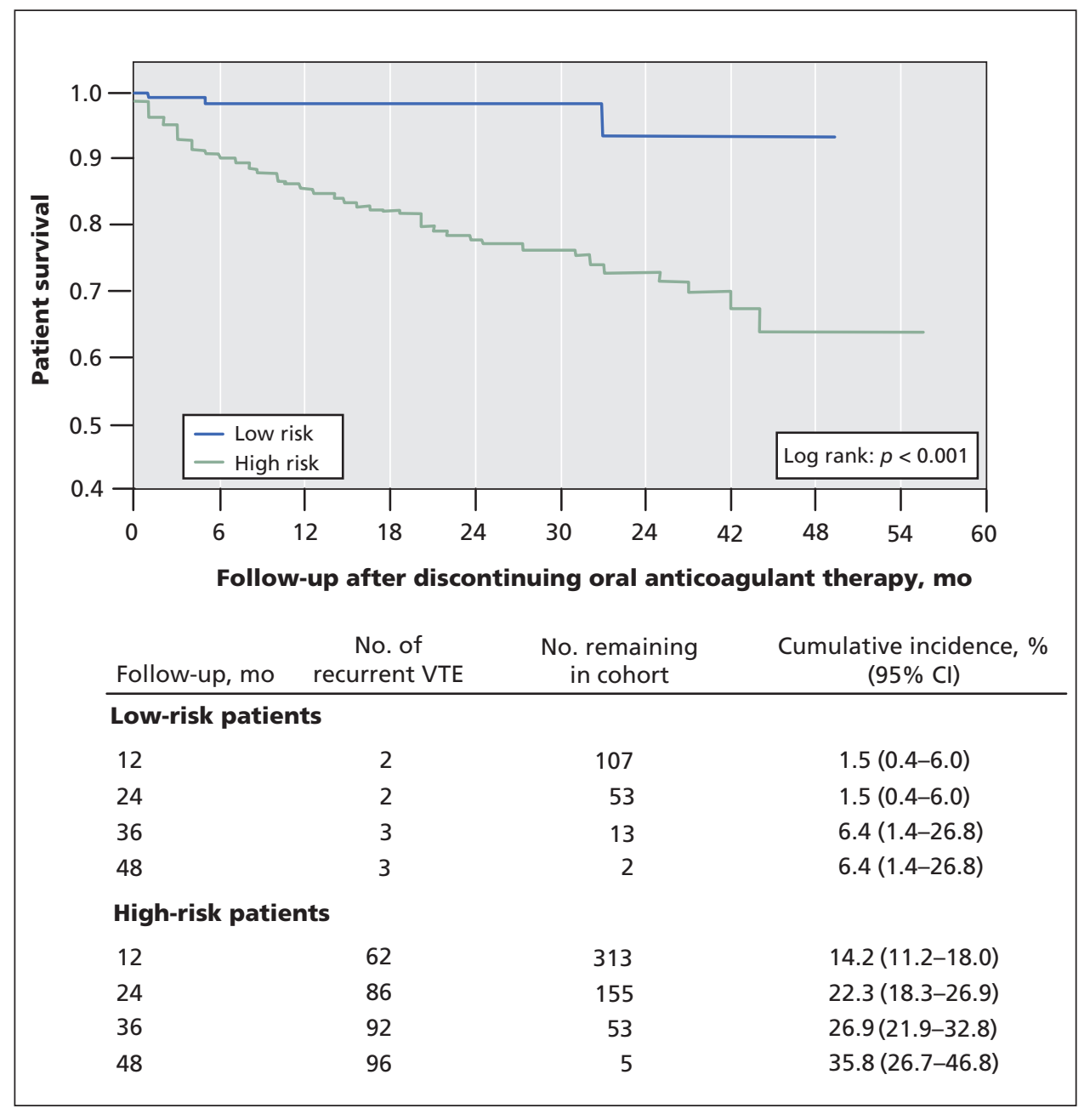

Figure 4: Survival estimates and cumulative risk of recurrent venous thromboembolism (VTE) after discontinuing oral anticoagulant therapy after 5-7 months. Patients were classified as low or high risk according to the candidate diagnostic rules for men and women. We performed the survival analysis with updated data in June 2007 (mean follow-up 22.5 months). Note: $\mathrm{Cl}=$ confidence interval. vated levels of factor VIII was a significant univariable predictor, but it was not an independent predictor in the multivariable analysis. In our study, no single predictor identified a sufficiently low-risk group to be clinically useful. A multivariable clinical decision rule is a more powerful approach because it combines the predictive power of multiple independent variables.

We identified 3 major novel findings. First, postthrombotic findings after 5-7 months of oral anticoagulant therapy are the strongest predictors of recurrent venous thromboembolism. Second, for women, but not for men, Ddimer levels (measured while taking oral anticoagulants) are an important predictor of recurrence after the patient has stopped taking anticoagulants. Third, we have identified a clinical decision rule that can be used to identify women at low risk of recurrence.

Our study has a number of strengths. To date, this is the largest and most comprehensive clinical study that has evaluated risk factors for recurrent venous thromboembolism in patients with unprovoked proximal deep vein thrombosis or pulmonary embolism. We prospectively measured all important risk factors potentially associated with recurrent venous thromboembolism in a standardized fashion. Our study included patients for whom the clinical decision to discontinue oral anticoagulation therapy is most uncertain, and we analyzed risk factors at the time when a decision is usually made. In addition, our study included a representative sample of patients from multiple centres and countries. These patients were consecutively enrolled without bias. The clinically relevant primary outcome of recurrent venous thromboembolism was clearly defined and independently adjudicated. We included only reproducible clinical variables in the final decision rule (age, BMI, ${ }^{27}$ Ddimer, ${ }^{28}$ post-thrombotic symptoms findings of hyperpigmentation, edema and redness ${ }^{29}$ ), which likely enhances the interobserver reproducibility of the rule. In addition, the 4 variables included in our decision rule all have face validity (i.e., make sense to clinicians) as predictors of recurrent venous thromboembolism. D-dimer levels, older age and increased BMI have been consistently shown to be predictors of recurrent venous throm-

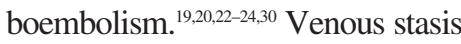
changes of hyperpigmentation, 
Box 1: Clinical decision rule* to identify women at low risk of recurrent venous thromboembolism after 5-7 months of oral anticoagulant therapy

Women with 0 or 1 of the following features may be able to safely discontinue therapy:

- Post-thrombotic signs (hyperpigmentation, edema or redness in either leg)

- D-Dimer level $\geq 250 \mu \mathrm{g} / \mathrm{L}$

- Body mass index $\geq 30 \mathrm{~kg} / \mathrm{m}^{2}$

- Age $\geq 65 \mathrm{yr}$

${ }^{*}$ Generated using the following logistic regression model: $Y=B_{1} X_{1}+B_{2} X_{2} \ldots$ recurrent venous thromboembolism $=-3.9717 \mathrm{x}$ (intercept) $+1.2977 \mathrm{x}$ (body mass index $\left.\geq 30 \mathrm{~kg} / \mathrm{m}^{2}\right)+0.6473 \times$ (either leg hyperpigmentation, edema or redness) $+0.9155 \times(\mathrm{D}$-dimer $\geq 250 \mu \mathrm{g} / \mathrm{L})+0.8084 \times$ (age $\geq 65 \mathrm{yr})$

edema or redness have been previously suggested to be predictors of recurrent venous thromboembolism. ${ }^{31,32}$ Because venous damage predisposes patients to slower and abnormal blood flow, the risk of recurrent venous thromboembolism should be increased among these patients.

Our study has several limitations. First, to avoid overfitting, not all potentially significant variables $(p<0.20)$ were included in our multivariable modelling. Second, not all patient data sets in the derivation group were complete. Third, D-dimer levels were measured and the optimal cut-off point (D-dimer $\geq 250 \mu \mathrm{g} / \mathrm{L}$ ) was identified by use of 1 reagent on 1 instrument. The use of other D-dimer tests will require separate studies to identify optimal cut-off points and performance in predicting recurrent venous thromboembolism within the context of this clinical decision rule. Fourth, our clinical decision rule does not predict how long anticoagulants should be continued for patients in the high-risk group. Randomized controlled trials that compare therapeutic options (shorter v. longer duration, higher v. lower intensity therapy, alternative anticoagulants) or risk stratification at a later time may be required to define optimal therapeutic management for high-risk patients. Fifth, we excluded patients with known high-risk thrombophilia, and few of our patients were nonwhite $(<8 \%)$, hence our clinical decision rule may not apply to patients in these groups. Finally, and most importantly, additional important methodologic criteria ${ }^{33,34}$ must be met before our decision rule can be widely adopted: the interobserver agreement of the rule must be determined, and the safety of this rule must be prospectively validated in a separate population to ensure that the low-risk group has less than $3 \%$ annual risk of recurrence.

We were unable to derive a rule that identified men at low risk who can safely discontinue anticoagulants after 5-7 months of therapy. It is possible that a larger sample would have permitted us to identify a low-risk group of men; however, it is likely that this subgroup would represent a small proportion of men given our sample size and that men had more recurrences than women (giving us more power to derive a rule in men). However, until a successful risk stratification tool is developed that identifies low-risk men, it appears that all men are at high risk of recurrence, particularly men with hyperpigmentation, edema or redness in either leg.
In conclusion, it may be safe for women who have taken oral anticoagulants for 5-7 months after an unprovoked venous thromboembolism to discontinue therapy if they have 0 or 1 of the following signs or symptoms: hyperpigmentation, edema or redness of either leg; a D-dimer level of $250 \mu \mathrm{g} / \mathrm{L}$ or more while taking warfarin; BMI $30 \mathrm{~kg} / \mathrm{m}^{2}$ or more; and age 65 years or more.

This article has been peer reviewed.

Competing interests: Marc Rodger has received consultant's fees (which were used to support his research) from bioMérieux, which has also provided travel assistance for study-related meetings to Dr. Rodger. Susan Kahn has received speaker's honoraria from Pfizer and Sanofi-Aventis and has participated on the advisory boards of Sanofi-Aventis and Bayer. Philip Wells has received speaker's honoraria from Dade Behring, bioMérieux, SanofiAventis, LEO Pharma and Organon. Isabelle Chagnon has received travel assistance from LEO Pharma to attend an international thrombosis and hemostasis meeting. Grégoire Le Gal has received travel funding from bioMérieux to attend steering committee meetings for this study and for a related study. Susan Solymoss has served as a consultant for Bayer, Boehringer Ingelheim, Pfizer and LEO Pharma, and has received speaker's fees from Pfizer and LEO Pharma. Richard White is a member of a safety-monitoring board run by Sanofi-Aventis. Tim Ramsay has received travel assistance from bioMérieux to attend a planning meeting for a follow-up study and has received an honorarium from bioMérieux used to fund a graduate student. None declared for David Anderson, Mark Crowther, Arnaud Perrier, Linda Vickars, Marisol Betancourt and Michael Kovacs.

Contributors: Marc Rodger and Michael Kovacs were the co-principal investigators. They, along with Susan Kahn, Philip Wells and David Anderson, designed and performed the research, collected and analyzed the data and wrote the manuscript. Grégoire Le Gal, Arnaud Perrier and Richard White performed the research, collected and analyzed the data and wrote the manuscript. Isabelle Chagnon, Susan Solymoss and Mark Crowther performed the research, collected the data and wrote the manuscript. Linda Vickars performed the research and collected the data. Tim Ramsay and Marisol Betancourt analyzed the data and wrote the manuscript. All of the authors revised the manuscript for important intellectual content and approved the final version submitted for publication.

Acknowledgements: This study was funded by the Canadian Institutes of Health Research (grant no. MOP 64319) and bioMérieux (through an unrestricted research grant).

Dr. Rodger had full access to all the data in the study and takes responsibility for the integrity of the data and the accuracy of the data analysis. All analyses were conducted independent of the funding sources.

\section{REFERENCES}

1. Baglin $\mathrm{T}$, Luddington $\mathrm{R}$, Brown $\mathrm{K}$, et al. Incidence of recurrent venous thromboembolism in relation to clinical and thrombophilia risk factors: prospective cohort study. Lancet 2003;362:523-6.

2. Buller HR, Agnelli G, Hull RD, et al. Antithrombotic therapy for venous thromboembolic disease: the Seventh ACCP Conference on Antithrombotic and Thrombolytic Therapy. Chest 2004;401S-28S.

3. Agnelli G, Prandoni P, Santamaria MG, et al. Three months versus one year of oral anticoagulant therapy for idiopathic deep venous thrombosis. Warfarin Optimal Duration Italian Trial Investigators. N Engl J Med 2001;345:165-9.

4. Kearon C, Gent M, Hirsh J, et al. A comparison of three months of anticoagulation with extended anticoagulation for a first episode of idiopathic venous thromboembolism. N Engl J Med 1999;340:901-7.

5. Prandoni P, Noventa F, Ghirarduzzi A, et al. The risk of recurrent venous thromboembolism after discontinuing anticoagulation in patients with acute proximal deep vein thrombosis or pulmonary embolism. A prospective cohort study in 1,626 patients. Haematologica 2007;92:199-205.

6. Ridker PM, Goldhaber SZ, Danielson E, et al. PREVENT I. Long-term, low-intensity warfarin therapy for the prevention of recurrent venous thromboembolism. $N$ Engl J Med 2003;348:1425-34.

7. Prandoni $\mathrm{P}$, Lensing AWA, Cogo A, et al. The long-term clinical course of acute deep venous thrombosis. Ann Intern Med 1996;125:1-7.

8. Columbus Investigators. Low molecular weight heparin in the treatment of patients with venous thromboembolism. N Engl J Med 1997;337:657-62. 
9. Douketis JD, Kearon C, Bates S, et al. Risk of fatal pulmonary embolism in patients with treated venous thromboembolism. JAMA 1998;279:458-62.

10. Agnelli G, Prandoni P, Becattini C, et al.; Warfarin Optimal Duration Italian Trial Investigators. Extended oral anticoagulant therapy after a first episode of pulmonary embolism. Ann Intern Med 2003;139:19-25.

11. Pinede L, Ninet J, Duhaut P, et al. Comparison of 3 and 6 months of oral anticoagulant therapy after a first episode of proximal deep vein thrombosis or pulmonary embolism and comparison of 6 and 12 weeks of therapy after isolated calf deep vein thrombosis. Circulation 2001;103:2453-60.

12. Kearon C, Ginsberg JS, Kovacs MJ, et al. Comparison of low-intensity warfarin therapy with conventional-intensity warfarin therapy for long-term prevention of recurrent venous thromboembolism. N Engl J Med 2003;349:631-9.

13. Linkins LA, Choi PT, Douketis JD. Clinical impact of bleeding in patients taking oral anticoagulant therapy for venous thromboembolism: a meta-analysis. Ann Intern Med 2003;139:893-900.

14. Agnelli G, Becattini C. Treatment of DVT: How long is enough and how do you predict recurrence? J Thromb Thrombolysis 2008;25:37-44. Epub 2007 Oct 1.

15. Wells PS, Rodger MA, Forgie MA, et al. The ACE D/D genotype is protective against the development of idiopathic deep vein thrombosis and pulmonary embolism. Thromb Haemost 2003;90:829-34.

16. Wells PS, Anderson DR, Rodger M, et al. Evaluation of D-dimer in the diagnosis of suspected deep-vein thrombosis. N Engl J Med 2003;349:1227-35.

17. Research Committee of the British Thoracic Society. Optimum duration of anticoagulation for deep-vein thrombosis and pulmonary embolism. Lancet 1992; 340:873-6.

18. Schulman S, Rhedin AS, Lindmarker P, et al. A comparison of six weeks with six months of oral anticoagulant therapy after a first episode of venous thromboembolism. Duration of Anticoagulation Trial Study Group. N Engl J Med 1995;332:1661-5.

19. Cosmi B, Legnani C, Cini M, et al. The role of D-dimer and residual venous obstruction in recurrence of venous thromboembolism after anticoagulation withdrawal in cancer patients. Haematologica 2005;90:713-5.

20. Eichinger S, Minar E, Bialonczyk C, et al. D-dimer levels and risk of recurrent venous thromboembolism. JAMA 2003;290:1071-4.

21. Kyrle PA, Minar E, Hirschl M, et al. High plasma levels of factor VIII and the risk of recurrent venous thromboembolism. N Engl J Med 2000;343:457-62.

22. McRae S, Tran H, Schulman S, et al. Effect of patient's sex on risk of recurrent venous thromboembolism: a meta-analysis. Lancet 2006;368:371-8.
23. Palareti G, Legnani C, Cosmi B, et al. Risk of venous thromboembolism recurrence: high negative predictive value of D-dimer performed after oral anticoagulation is stopped. Thromb Haemost 2002;87:7-12.

24. Palareti G, Cosmi B, Legnani C, et al. PROLONG I. D-Dimer testing to determine the duration of anticoagulation therapy. N Engl J Med 2006;355:1780-9.

25. Piovella F, Crippa L, Barone M, et al. Normalization rates of compression ultrasonography in patients with a first episode of deep vein thrombosis of the lower limbs: association with recurrence and new thrombosis. Haematologica 2002;87: $515-22$

26. Prandoni $\mathrm{P}$, Lensing AW, Prins $\mathrm{MH}$, et al. Residual venous thrombosis as a predic tive factor of recurrent venous thromboembolism. Ann Intern Med 2002;137:955-60.

27. Schreiner PJ, Pitkaniemi J, Pekkanen J, et al. Reliability of near-infrared interactance body fat assessment relative to standard anthropometric techniques. J Clin Epidemiol 1995;48:1361-7.

28. Pittet JL, de Moerloose P, Reber G, et al. VIDAS D-dimer: fast quantitative ELISA for measuring D-dimer in plasma. Clin Chem 1996;42:410-5.

29. Roger MA, Khan SR, Le Gal G, et al. Inter-observer reliability of measures to assess the post-thrombotic syndrome. Thromb Haemost 2008;100:164-6.

30. Heit JA, Mohr DN, Silverstein MD, et al. Predictors of recurrence after deep vein thrombosis and pulmonary embolism: a population-based cohort study. Arch Intern Med 2000;160:761-8

31. Schulman S, Lindmarker P, Holmstrom M, et al. Post-thrombotic syndrome, recurrence, and death 10 years after the first episode of venous thromboembolism treated with warfarin for 6 weeks or 6 months. J Thromb Haemost 2006;4:734-42.

32. Stain M, Schonauer V, Minar E, et al. The post-thrombotic syndrome: risk factors and impact on the course of thrombotic disease. J Thromb Haemost 2005:3:2671-6.

33. Laupacis A, Sekar N, Stiell IG. Clinical prediction rules. A review and suggested modifications of methodological standards. JAMA 1997;277:488-94.

34. Wasson JH, Sox HC, Neff RK, et al. Clinical prediction rules. Applications and methodological standards. N Engl J Med 1985;313:793-9.

Correspondence to: Dr. Marc Rodger, Division of Hematology, The Ottawa Hospital, General Campus, 501 Smyth Rd., Ottawa ON K1H 8L6; fax 613 739-6102; mrodger@ohri.ca

\section{Holiday Reading}

\section{Call for submissions}

Do you have something profound or profoundly entertaining to say? CMAJ may be just the place to publish. In December 2008, we will present a special Holiday Reading section - a deviation from our usual Holiday Review fare. The section will feature essays, creative non-fiction, short fiction and narrative medicine articles. Your missive can be ethical or satirical, personal or academic, plainly frivolous or gratuitously entertaining; the common thread is medicine in all its permutations.

Articles should be no longer than 1200 words; photographs and illustrations are welcome. Send your submissions for consideration via our online manuscript system (http://mc.manuscript central.com/cmaj). Please mention in your cover letter that your submission is intended for this year's Holiday Reading issue.

The deadline for submissions is Oct. 7, 2008.

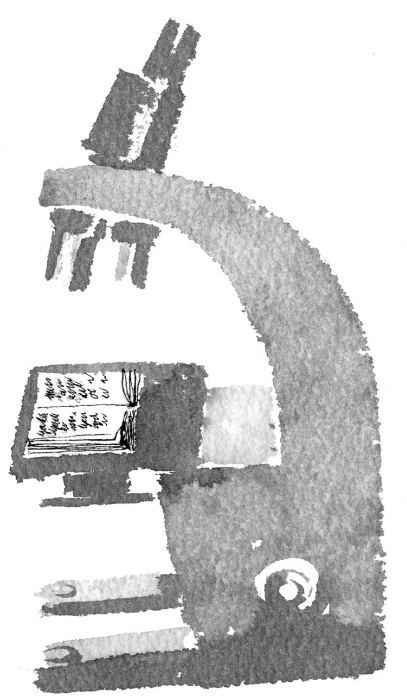

